\title{
Review \\ Normal stem cells in cancer prone epithelial tissues
}

\author{
TJ Phesse' and AR Clarke*,I \\ 'Department of Biosciences, Cardiff School of Biosciences, Cardiff University, PO Box 91 I, Cardiff, CFIO 3US, UK
}

The concept of a cancer stem cell is not a new one, being first suggested over 100 years ago. Over recent years the concept has enjoyed renewed enthusiasm, partly because of our growing understanding of the nature of somatic stem cells, but also because of a growing realisation that the development of strategies that target cancer stem cells may offer considerable advantages over conventional approaches. However, despite this renewed enthusiasm the existence of cancer stem cells remains controversial in many tumour types and any potential relationship to the normal stem cell pool remains poorly defined. This review summarises key elements of our understanding of the normal stem cell populations within animal models of the predominant cancer prone epithelial tissues, and further investigates the potential links between these populations and putative cancer stem cells. British Journal of Cancer (2009) 1 00, 22 I-227. doi: 10.1038/sj.bjc.6604850 www.bjcancer.com

Published online 6 January 2009

(c) 2009 Cancer Research UK

Keywords: stem cell; cancer stem cell; animal models; markers; epithelium

\section{CANCER PRONE TISSUES}

Of approximately 200 different types of cancer, four account for over half of all the new cases diagnosed in Britain every year breast, lung, colorectal and prostate (Toms, 2004). There is also a fifth type of, cancer which evades the national statistics database as it is regularly diagnosed and successfully treated within GP surgeries - non-melanoma skin cancer (NMSC) (Toms, 2004). It is estimated that at least 100000 cases of NMSC are diagnosed each year in the United Kingdom, which is higher than the sum total of breast and lung cases combined (Toms, 2004). This figure is on the increase and consequently the skin can also be considered as a cancer prone organ.

The lung represents a rather special case for inclusion as a cancer prone tissue. In the early 1900s lung cancer was a rare disease in the UK, but rates increased to a peak in the late 1970s when smoking was at its most popular. As the number of people smoking is slowly decreasing, so the cases of lung cancer are also beginning to decrease. In fact, the lungs have a remarkable capacity to regenerate and repair damaged tissue. This suggests that, aside from tobacco exposure, the lungs are actually comparatively cancer resistant. However, while smoking persists as a global habit the frequency of lung cancer will remain high and therefore knowledge regarding lung stem cells is of potential value for the development of future therapies.

\section{STEM CELLS WITHIN EPITHELIAL TISSUES}

Epithelial layers are composed of a sheet of cells (or multiple sheets), which constitute the linings and surfaces of the body. The epithelium provides a physical barrier from the external environment, facilitating the absorption of water and nutrients,

* Correspondence: Professor AR Clarke; E-mail: Clarkear@cf.ac.uk Received I4 April 2008; revised I December 2008; accepted 3 December 2008; published online 6 January 2009 and regulating glandular secretions. Epithelial layers are thought to be maintained by a small population of tissue-specific adult somatic stem cells, which have the potential to produce all the different cell types present in the tissue they reside in. Even organs which were considered to consist entirely of terminally differentiated cells, such as the brain, have been shown to contain small populations of pluripotent cells with a high capacity to divide and differentiate into the major cell types of the nervous system (Reynolds and Weiss, 1996).

The current model of adult epithelial somatic stem cells has been obtained from work performed primarily in organs, which have a high proliferative capacity such as the intestine, skin and mammary gland. Adult epithelial somatic stem cells are found in very low numbers and are protected in well vascularised niches which provide essential cues to strictly regulate their function (Scadden, 2006). Stem cells are characterised by two functions (reviewed in Reya et al, 2001). First, they are able to self-renew. Second, through asymmetric division, they are able to produce progenitor cells which initially bear very similar characteristics to the stem cell, but become less able to self-renew with each subsequent division, and eventually stop dividing and terminally differentiate into a mature tissue-specific cell type. Through this mechanism stem cells are able to produce all the multiple cell types found in the tissue from which they reside. The daughter cells also have a high proliferation rate and are often termed transitamplifying cells. It is the transit-amplifying cells that provide the number of cells required for homoeostasis of the tissue in which they reside, as endogenous somatic stem cells are normally considered to have a low frequency of division (replicative quiescence).

\section{PROSTATE}

Although the prostate is a relatively quiescent organ with regards to proliferation, it has considerable regenerative capacity. For 
example, castration-induced involution of the prostate in rodents can be completely rescued if androgen is resupplied - a cycle that can be repeated up to 30 times in the same animal (Isaacs, 1985).

Several molecular markers of the prostatic stem cell have recently been proposed, including $\alpha_{2} \beta_{1}$ integrin in conjunction with CD133 (Richardson et al, 2004; Tsujimura et al, 2007) and Sca-1 (Xin et al, 2005). Human $\alpha_{2} \beta_{1}^{\mathrm{hi}} / \mathrm{CD} 133^{+}$-enriched cells were able to establish and maintain a prostate epithelium when transplanted in to an immunodeficient mouse, although an entire, functional prostate organ did not develop (Richardson et al, 2004). The mouse homologue of CD133, prominin, also enriched for cells which displayed stem cell properties in vitro, and is expressed in the basal layer of the proximal region of the mouse prostate (Tsujimura et al, 2007). Similar results were observed in mice using Sca-1 enriched cells, which were able to display stem cell qualities in vivo and initiate tumourigenesis in conjunction with activated AKT (Xin et al, 2005).

Recently, Lawson et al (2007) demonstrated that a $\mathrm{CD}_{4} 5^{-}$/ CD $31^{-} /$Ter $119^{-} / \mathrm{Sca}-1^{+} / \mathrm{CD}_{4} 9 \mathrm{f}^{+}$cell subpopulation isolated from mouse prostate is enriched for cells capable of both colony and sphere formation in vitro. These cells can also differentiate to produce prostatic tubule structures in vivo, containing both basal and luminal cells, when injected subcutaneously into SCID mice. However, only 1 in 35 enriched cells was capable of developing prostate structures in vivo, suggesting that the stem cell is not defined by these markers and that further markers are also required to be expressed correctly (positively or negatively) (Lawson et al, 2007). CD $45^{-} \mathrm{CD}^{-} 1^{-}$Ter $119^{-} \mathrm{Sca}^{+}{ }^{+} \mathrm{CD}_{49 \mathrm{f}^{+}}$ enriched cells localised to the basal layer within the proximal region of the prostate after injection suggesting that this is the endogenous location of stem cells in the murine prostate (Figure 1).

To date, none of the enriched cells used for in vivo assays has developed into an entire functional prostate, demonstrating that although these enriched cells have stem-like qualities they do not possess all the unique properties required for total organ regeneration.

The markers used to enrich for potential prostate stem cells have also been used to enrich cells which have stem cell properties in other epithelial tissues, including brain (CD133 (Singh et al, 2003)), mammary gland (CD133 (Tsujimura et al, 2007)); CD49f (Stingl et al, 2006) and lung (Sca1, (Kim et al, 2005)), suggesting significant common features between stem cells of different tissues.

\section{MAMMARY}

The Mammary gland is composed of a branching network of ducts that terminate in sac-like lobules (Figure 1). The massive expansion of epithelium during puberty and pregnancy, together with the remarkable regenerative capacity of successive reproductive cycles, suggests that the mammary epithelium contains a population of somatic stem cells.

Cell surface markers $\left(\mathrm{CD} 24^{\text {med }} \mathrm{CD} 49 \mathrm{f}^{\text {hi }}\right)$ have been used to isolate cell populations from adult murine mammary gland enriched for the capacity to initiate new mammary outgrowths when transplanted into the epithelial-free fat pads (Stingl et al, 2006). The existence of a mammary stem cell has now clearly been demonstrated using cell surface markers ( $\operatorname{Lin}^{-} \mathrm{CD} 29^{\mathrm{hi}} \mathrm{CD} 24^{+}$) to enrich for a single basal/myoepithelial cell from the murine mammary gland that was able to reconstitute an entire functional gland using the same assay (Shackleton et al, 2006). These cells are slow-cycling and express a number of genes that have been implicated as stem cell markers in other tissues such as Sca-1 in the prostate (Xin et $a l, 2005$ ) and keratin 14 in the skin (Morris et al, 2004). However, not all Lin $^{-}$(CD45, Ter119 and CD31 collectively called Lin) $\mathrm{CD} 29^{\text {hi }} \mathrm{CD} 24^{+}$cells were capable of reconstituting a functional mammary gland - only six out of 102 implanted single cells. Thus, the exact nature of the stem cell is unknown, and further markers, in addition to $\operatorname{Lin}^{-} \mathrm{CD} 29^{\mathrm{hi}}$ $\mathrm{CD}_{2} 4^{+}$, are also required to genuinely define the stem cell population.

The precise location of the mammary stem cell remains uncertain, but molecular features such as keratin 14 indicate a basal position in the mammary epithelium of the adult gland (Stingl et al, 2006) (Figure 1).

\section{SKIN}

The skin epidermis is a stratified (layered) squamous epithelium containing hair follicles and sebaceous glands (Figure 1). The interfollicular epidermis (IFE) is composed of a basal layer of proliferative cells, which then differentiate into the distinct suprabasal layers above. The suprabasal layers are continually replaced by cells from the basal layer as the stratum corneum is sloughed off. This constant regeneration is strongly suggestive of a resident population of stem cells in the basal layer of the skin (Blanpain et al, 2004).

The adult hair follicle undergoes a periodic cycle of growth, destruction and rest which requires a population of stem cells that reside in a region called the bulge, located under the sebaceous gland (Figure 1) (Blanpain et al, 2004). Transplantation of a dissected bulge region into an immunodeficient (NOD/SCID) mouse demonstrated that transplanted cells were able to differentiate into all the epithelial cell types of the skin (Oshima et al, 2001). Subsequent to this experiment, CD34 ${ }^{+} \alpha 6$ integrin $^{+}$ enrichment was used to isolate a single cell from the bulge region. Transplantation of these cells into a nude mouse resulted in tufts of hair at the graft site, and lineage tracing revealed contribution of the grafted cell to the epidermis, sebaceous glands and hair follicle (Blanpain et al, 2004). These results demonstrated the multipotency of $\mathrm{CD}_{3} 4^{+} \alpha 6$ integrin $^{+}$-enriched cells from the bulge and consequently their definition as genuine stem cells.

Lineage tracing experiments in mice using a non-invasive transgenic approach have indicated that a stem cell population also exists in the IFE to facilitate the continuous renewal of the skin (Ro and Rannala, 2004). However, interfollicular stem cells have yet to be isolated, and there are no reliable markers of this population at present. There is also evidence from lineage tracing of IFE progenitors to suggest that IFE homoeostasis occurs independently from stem cells, instead utilising a single population of persistent progenitors (Clayton et al, 2007). This has also been observed during repair of the pancreas after injury (Dor et al, 2004) and challenges the 'stem cell/transit-amplifying cells' model by suggesting that progenitor cells are not always transient, and that differentiated cells can divide to maintain homoeostasis of adult tissues.

\section{INTESTINE}

The mammalian intestinal epithelium consists of a single layer of epithelial cells, which are organised into finger-like projections (villi) that extend into the lumen of the gut and pocket shaped crypts at the base (Figure 1). BrdU label-retaining assays suggest that the stem cells reside in the crypt (Potten et al, 2002), but unlike the work performed on the cornea (Cotsarelis et al, 1989) and hair follicle (Cotsarelis et al, 1990), no functional assay has yet been performed to confirm this.

Each adult crypt is monoclonal, but the villi are polyclonal and contain cells from several crypt. Therefore each crypt contains a single active stem cell (Figure 1). However, actions that are deleterious to the endogenous stem cell, such as exogenous DNA damage or the removal of crucial transcription factors such as C-Myc (Muncan et al, 2006), triggers the death of the stem cell and 

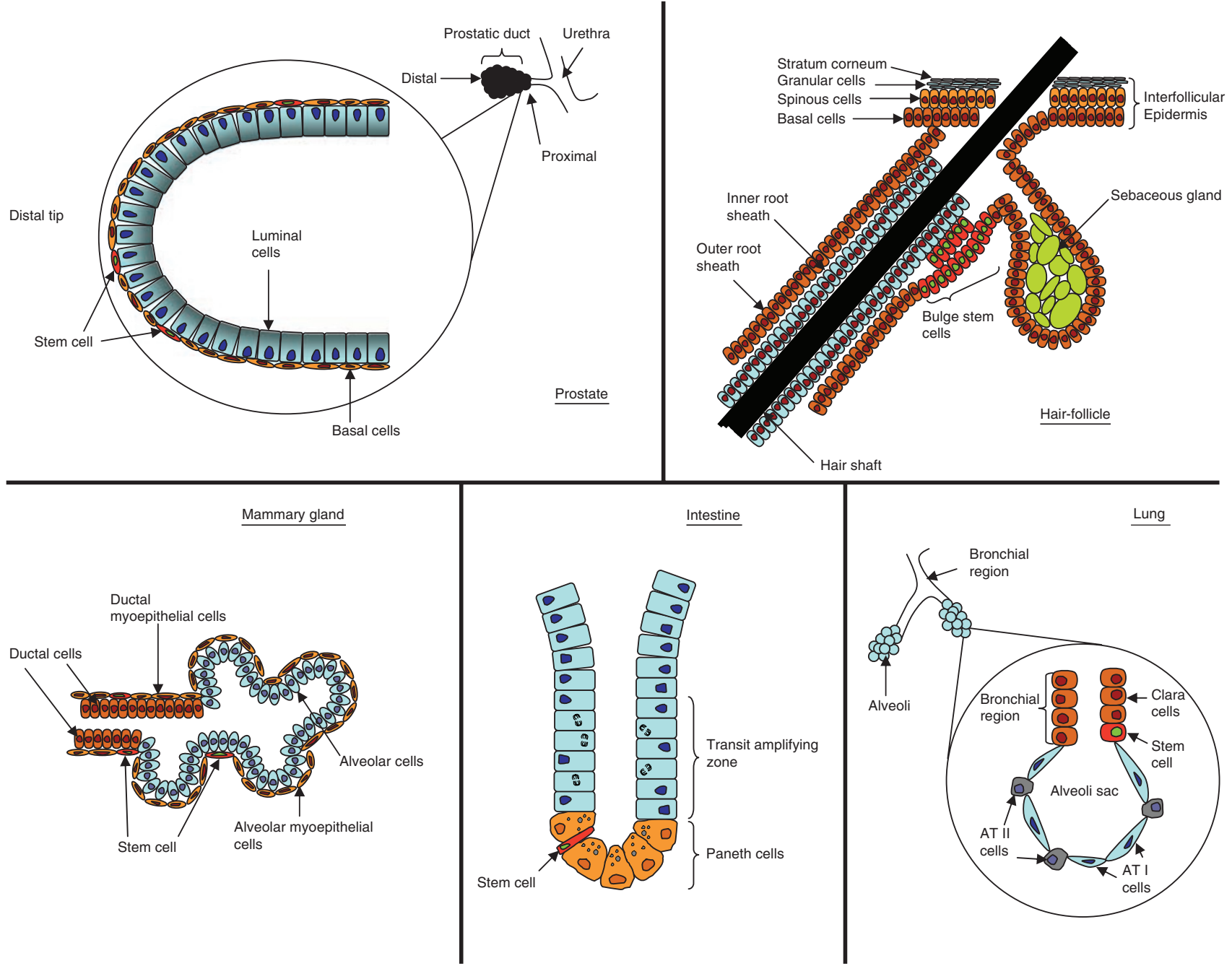

Figure I Location of stem cells. Prostate gland. The putative prostatic stem cells are located in the basal cells surrounding the columnar secretory cells of the distal prostatic duct. Hair-follicle. Skin stem cells are located under the sebaceous gland in a region known as the bulge. During rest periods, stem cells of the bulge region form the base of the hair-follicle. During the start of each new growth cycle stem cells located at the base of the bulge become active to form the highly proliferative new hair germ. The interfollicular epidermis is a stratified epithelium, containing unipotent progenitor cells and transit-amplifying cells located in the basal layer. Basal cells differentiate upward to form the spinous, granular, and stratum corneum layers of the epidermis. Mammary gland. The mammary gland consists of a branching network of ducts, terminating in alveolar buds. Mammary stem cells are thought to be located in the basal, myoepithelial layer, which tightly surrounds the ductal epithelial layer. The secretory alveolar cells are also surrounded by a looser association of myoepithelial cells. Intestinal crypt. The crypt stem cell had previously been located to position 4-6, just above the base of the crypt. Recent data now suggests the putative stem cells of the intestine (red) are narrow cells located between Paneth cells near the base of the crypt. Cells leaving the proliferation zone migrate upward towards the villus tip and differentiate into one of three cell types, enteroendocrine cells, goblet cells, and enterocytes, to form the villus. A fourth cell type, the Paneth cells, migrate downward to the crypt base. Lungs. The putative lung stem cells are located at the junction between the branching, bronchial region and the alveolar sac, and express markers from ATII cells and Clara cells.

subsequent re-population of the crypt from a previously quiescent stem cell.

The characterisation of intestinal stem cells has proved challenging, and presently there is no direct functional assay. Several molecules have been proposed to mark the intestinal stem cell population, such as Musashi and phospho-Pten (He et al, 2007). However, these remain unproven as definitive markers of the intestinal stem cell. Recently, there has been a significant advance from Hans Clevers' laboratory, based on a screen of Wnt target genes (Barker et al, 2007). Wnt signalling is critical for both the development of the intestine and the homoeostasis of the adult tissue (Clarke, 2006). Deregulation of the Wnt pathway by removal of $A p c$ from the adult murine intestine immediately imposes a phenotype mimicking tumourigenesis (Sansom et al, 2004), a phenotype entirely dependent on the Wnt target C-Myc (Sansom et al, 2007). Based on array data, it was speculated that the intestinal stem cell will express some Wnt target genes. One of these Wnt targets, Lgr5, a G-protein-coupled receptor gene, was found to be expressed in slender cells between the Paneth cells at the base of the crypt (Barker et al, 2007). Previously, long-term label-retaining experiments had suggested the putative stem cell was located just above the Paneth cells at position 4-6 (Potten et al, 1997). Lineage tracing using a Cre inducible Lac- $Z$ has now shown that $\operatorname{Lgr} 5^{+}$cells give rise to all intestinal epithelial cells over a 60 -day period, strongly suggesting that Lgr5 $^{+}$cells are either synonymous with the intestinal stem cell, or that they are markedly enriched for the intestinal stem cell (Barker et al, 2007).

Unlike stem cells discovered in other organs such as the skin and mammary gland, the Lgr $5^{+}$intestinal stem cells do not have a slow rate of division. Conversely, they appear to divide frequently, a condition which may reflect the fact that the intestine is the most rapidly self-renewing tissue in adult mammals (Barker et al, 2007). 
Such a finding questions the sole use of label-retaining cells as a reliable marker of the stem cell population in all tissues.

Despite these very clear observations, some debate still remains over the precise nature of the intestinal stem cell. Most notably, very similar approaches to those described above have been used by Sangiorgi and Capecchi (2008) to show that Bmi-1 expression marks the stem cell, and indeed deletion of Bmi-1-expressing cells results in crypt ablation. However, the reported positioning of Bmi-1 positive cells does not precisely overlap with Lgr5 positivity, suggesting that actually there may be two pools of molecularly identifiable populations of stem cells within the intestine.

\section{LUNG}

The ability of the lungs to repair and regenerate prior to smoke damage suggests there is a pool of lung stem cells. However, the pulmonary system has proven a particularly challenging environment to study stem cells due to its complex structure, which contains multiple, distinct epithelial regions including pseudostratified epithelium, columnar epithelium and alveolar epithelium.

The bronchial epithelial regions are composed mostly of Clara cells, while the alveolar epithelium consists of type I and type II (AT2) cells (Figure 1). Clara cells and AT2 cells have both been implicated as the cells of origin in adenocarcinomas (Neuringer and Randell, 2004). However, work from Tyler Jacks' lab on mice has identified a small population of cells that express both AT2specific markers and Clara cell markers (Kim et al, 2005). These cells, termed BASCs (bronchioalveolar stem cells), were found in mutant $K$-ras induced adenocarcinomas and at the bronchioalveolar duct junction of normal lung tissue. In vivo they proliferated in response to epithelial damage, and exhibited stem cell characteristics such as self renewal and multipotency when isolated and cultured. Enrichment of BASCs in K-ras induced tumorigenesis resulted in an increase in tumour number and size suggesting that transformed BASCs also play a role during tumorigenesis in the lung (Kim et al, 2005), although this is yet to be confirmed in an in vivo assay.

Molecular analysis of BASCs revealed that they were Sca1 ${ }^{+}$ $\mathrm{CD}^{-} 5^{-} \mathrm{Pecam}^{-} \mathrm{CD}^{+} 4^{+}$(Kim et al, 2005). These molecules are also markers of proposed stem cells from other epithelial tissues including prostate $\left(\mathrm{Scal}^{+}\right.$; Xin et al, 2005) and $\mathrm{CD}^{-} 5^{-}$; Lawson et al, 2007) and skin $\left(\mathrm{CD}^{+} 4^{+}\right.$; Blanpain et al, 2004), again suggesting considerable overlap between stem cells from different organs.

\section{CANCER STEM CELLS}

Not all the cells within a tumour are able to proliferate when isolated from the tumour and grown in culture or transplanted into a new host. In fact only a very small percentage of cells within a tumour have the potential to reconstitute a new tumour upon transplantation (one in every $5.7 \times 10^{4}$ for colon tumours; O'Brien et al, 2007). This suggests there is a small subpopulation of highly prolific cells that have tumorigenic potential. The first evidence for such a population derives from studies by Bonnet and Dick (Bonnet and Dick, 1997). They demonstrated that only a subpopulation of $\mathrm{CD} 34^{+} \mathrm{CD} 38^{-}$cells, purified from patients with acute myeloid leukaemia, were able to transfer the disease to immunodeficient (NOD/SCID) mice.

Since then, cancer stem cells have also been identified through similar experiments using cell surface markers such as CD133. Given that stem cells share some common properties, it is perhaps not surprising that cancer stem cells from different tissues have some common markers. For example, $\mathrm{CD}_{133^{+}}$cells have been used to enrich for cancer stem cells in both the brain (Singh et al, 2004) and colon (O'Brien et al, 2007; Ricci-Vitiani et al, 2007), and skin and mammary stem cells both express high levels of $\beta 1$-integrin and $\alpha 6$-integrin (Shackleton et al, 2006).

These experiments strongly support the widespread existence of cancer stem cells; however, the concept still remains controversial for many tumour types. This has been most clearly argued by Strasser and co-workers (e.g., Kelly et al, 2007), who have shown that a variety of leukaemias and lymphomas can be maintained by syngeneic transfer of dominant populations, rather than minority 'cancer stem cell' populations. They suggest that the observation of minority 'cancer stem cells' is often a reflection of the experimental system used, for example the use of xenotransplantation assays into a foreign microenvironment.

In summary, the evidence in favour of cancer stem cells remains strong, but significant issues and doubts remain, which predominantly arise from uncertainties about the assays in use. At this point it seems reasonable to conclude that minority 'stem cell' populations do exist within some cancers; however, the broad applicability of this concept to all tumours remains unproven.

\section{FUNCTIONAL ASSAYS FOR STEM CELLS AND CANCER STEM CELLS}

A functional assay for somatic 'stemness' is the ability of a single isolated cell from an adult organ to generate an entire organ when transplanted. Thus far, this has only been successfully achieved for the skin and mammary gland. Although this is the ultimate experiment to test for stem cell activity, it is also very difficult to achieve with stem cells from epithelial origins. Epithelial layers are in contact with many other cell types and tissues such as fibroblasts, extra cellular matrix and mesenchyme, which constantly cue and interact with the epithelium. These signals, such as Wnt and Notch, are critical for the survival and function of somatic stem cells and pose the challenge of delivering a proposed somatic stem cell directly into its tissue niche.

Although there are many examples of somatic stem cells, which can display the characteristics of stem cells in vitro (Table 1), the next step in defining them as a true stem cell is to develop functional in vivo assays for these isolated cells. For example, only one in every $262 \mathrm{CD} 33^{+}$cells was able to initiate colon cancer (O'Brien et al, 2007), demonstrating that although CD133 is a marker for potential cancer stem cells it is not a definitive marker for this tissue. A similar situation pertains to the proposed prostate stem cell marker Sca-1. Sca- ${ }^{+}$cells can produce prostatic tubules when transplanted under the kidney capsule of immunodeficient mice, however, although the structures are smaller, Scal ${ }^{-}$cells possess the same ability (Xin et al, 2005). Recently CD34 has been used to enrich a population of cells from a mouse skin tumour which are able to generate secondary and tertiary tumours upon transplantation (Malanchi, 2008). Although CD34-positive cells are potent tumour-initiating cells in comparison to unsorted tumour cells, the frequency of tumour initiation decreases when the number of CD34 + cells is reduced. Thus, CD34 expression alone is not sufficient to mark a skin cancer stem cell but in addition genes, which currently remain unknown are also required to be correctly expressed. Therefore, although markers are currently being identified that often enrich for stem cells and cancer stem cell populations, these markers are, as yet, often not definitive.

\section{CANCER STEM CELLS AND NORMAL STEM CELLS}

The central question of this review is whether the two populations of normal and neoplastic stem cells are related. It has been selfevident for many years that there are strong parallels between 'stemness' and neoplasia. This is particularly clear from the development of multipotent embryonal carcinoma cells and subsequently genuine pluripotent embryonic stem cells, the latter 
Table I Functionally defined proposed stem cell and cancer stem cell markers from animal models

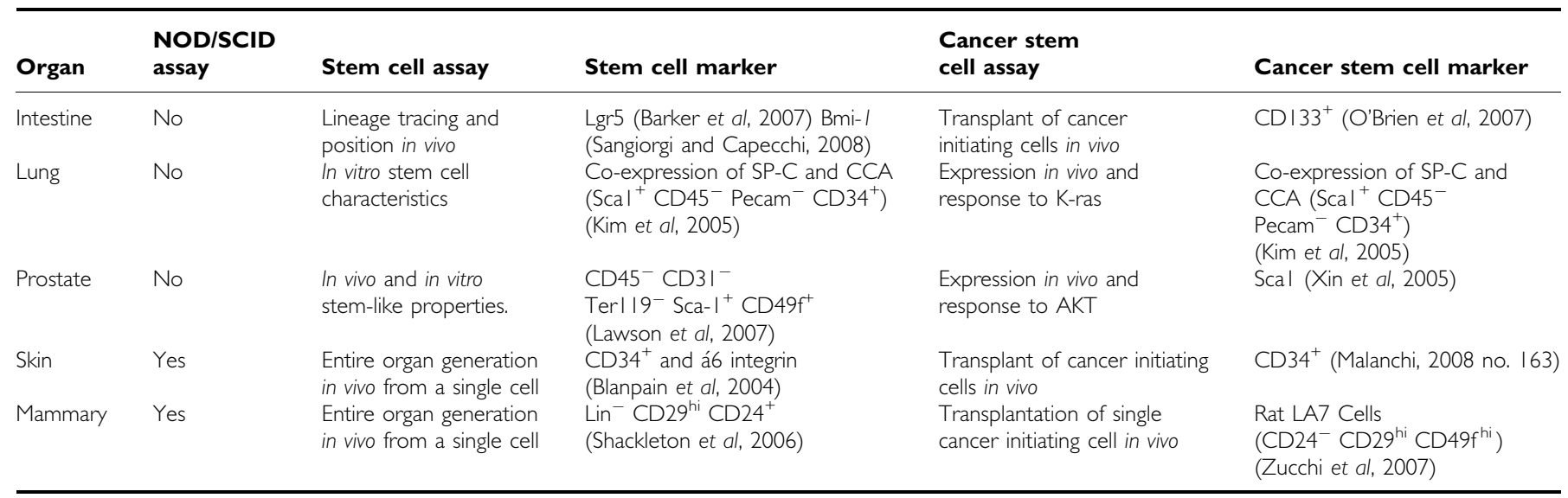

from teratoma prone mice (Solter, 2006). It is becoming apparent that normal stem cells and cancer stem cells share some common characteristics. These include the signalling pathways that have been implicated in the normal regulation of somatic stem cells, such as the Wnt pathway, which are often deregulated during tumorigenesis.

It is also evident that somatic stem cells possess properties that may render them more prone to transformation. For example, as stem cells usually remain in a given tissue for much longer than their differentiated progeny, the lifetime opportunity to acquire transforming mutations may be increased. In the intestine, differentiated cells are sloughed into the intestinal lumen over the course of four-five days, giving a very short window for a transformed phenotype to manifest. By contrast, intestinal stem cells persist in the epithelium to replace the transit-amplifying cells that are lost, and so offer a semi-permanent target population for transformation.

The capacity for self renewal may be considered a similar proneoplastic factor. The increasing cell mass of a tumour must contain cells with the ability to self-renew. As stem cells inherently possess this mechanism, the path to a functional cancer stem cell may therefore be considerably shorter than that for a differentiated somatic cell, which may have to acquire specific mutations to achieve the same self-renewing properties.

In terms of the cancer stem cell examples given above, examples of overlap between the normal and cancer stem cell populations are already beginning to emerge. For example, although little is known regarding its function, $\mathrm{CD} 133^{+}$cells isolated from either normal prostate tissue (Richardson et al, 2004) or brain tumours (Singh et al, 2003) continued to display somatic stem cell properties in vitro.

The skin stem cell marker CD34 (along with $\alpha 6$ integrin $^{+}$) is also expressed in skin tumours, and has recently been used to enrich a population of skin tumour cells with potent tumour initiation properties (Malanchi, 2008 no. 163). This common marker suggests that skin stem cells are potential targets for transformation into cancer stem cells; however, the regulation of the skin stem cells and skin cancer stem cells appears to differ. Depletion of $\beta$-catenin from skin tumours resulted in the loss of CD34 expression and total regression of the tumour suggesting that skin cancer stem cells require Wnt signalling. This is supported by experiments in which c-Myc (a Wnt target) deficient epidermis is resistant to Ras-induced tumorigenesis through repression of p21 ${ }^{\mathrm{Cip} 1}$ (Oskarsson, 2006 no. 162). However, c-Myc is surprisingly dispensable for skin homoeostasis indicating that it may be an attractive target for therapeutic intervention, which does not affect normal stem cells. This is not the case in all organs, as $\mathrm{c}-\mathrm{Myc}$ is not dispensable for homoeostasis in the intestine (Muncan et al, 2006 no. 114).

Similarly, single rat LA7 cells (six out of nine injections) are able to initiate the formation of mammary tumours when injected into the fat pads of immunodeficient mice, suggesting they are functional cancer stem cells (Zucchi et al, 2007). However, they also exhibit somatic stem properties in vitro, including both self renewal and the ability to differentiate into all lineages of the mammary gland (Zucchi et al, 2007). LA7 cells also express cell surface markers used to enrich for normal mouse mammary cells such as CD29 (Shackleton et al, 2006) and CD49f (Stingl et al, 2006). Interestingly, the expression of CD24, which was high in normal murine mammary stem cells (Shackleton et al, 2006), is low in LA7 cells (Zucchi et al, 2007) and human mammary cancer stem cells (Al-Hajj et al, 2003), suggesting a crucial difference between normal and cancer mammary stem cells which could be exploited for future therapies.

A definitive comparison between the mammary stem cells used to derive an entire functional mammary gland ( $\mathrm{Lin}^{-} \mathrm{CD} 29^{\text {hi }}$ $\mathrm{CD}^{+} 4^{+}$) (Shackleton et al, 2006) and mammary cancer stem cells (Zucchi et al, 2007) cannot be confidently made as yet, as only approximately $10 \%$ of the single cells implanted were able to develop into a functional mammary gland. Thus, we cannot say with any certainty whether the cancer stem cell and somatic stem cell are exactly the same as certain essential properties are unknown.

The recently identified intestinal stem cell marker Lgr5 is also expressed in hair follicle stem cells, as well as tumour tissue from the colon, liver and ovaries (Barker et al, 2007). Very recent unpublished data from Hans Clevers' lab has shown that Lgr5 ${ }^{+}$ cells isolated from the bulge region of the hair follicle have the capacity to form a new hair follicle in vivo (Jaks et al, 2007). This type of in vivo assay is difficult to perform in the intestine, but suggests that $\operatorname{Lgr}^{+}$could be a genuine marker of stem cells in several tissues. Importantly, Lgr $5^{+}$cells in the bulge region are cycling, and do not overlap with long-term label-retaining cells which are thought to mark stem cells of many tissues including the intestine where Lgr5 was first identified. These data further question the validity of using long-term label-retention as a surrogate marker of stem cells in adult tissues.

There is growing evidence demonstrating the similarities between cancer stem cells and normal stem cells, however, this does not prove that cancer stem cells originate from transformed normal somatic stem cells located in the same tissue. This raises the important issue of stem cell plasticity within tissues, with the 
possibility that both normal and cancer 'stemness' can be acquired from a differentiated phenotype. For normal stem cells, this is readily demonstrated in the mouse intestine by the recruitment of a novel population of stem cells following DNA damage. For cancer cells, nuclear transplantation has been used to clearly show that reprogramming within an oocyte can re-establish almost full developmental pluripotency (Hochedlinger et al, 2004). Notably, these latter experiments were not performed with cells enriched for a cancer 'stem cell' phenotype, suggesting that the capacity for pluripotency may be retained at a relatively high level within tumours. Recently, a mechanism for such reprogramming has been at least partially characterised, as mouse embryonic fibroblasts have been reprogrammed into ES-like cells through a co-ordinated expression of Oct4, c-Myc, Klf4 and Sox2 (Wernig et al, 2007).

Ultimately, there is a need to directly address the relevance of normal cancer cells to cancer initiating cells and cancer sustaining cells. Two experiments have recently begun to address this in the intestine using the normal stem cell markers bmi-1 and Lgr5. Both Sangiorgi et al (2008) and Barker et al (2008) have used these markers to drive expression of Cre recombinase within the intestinal stem cell and thereby deregulate the Wnt pathway, either by activation of beta-catenin or inactivation of $A p c$. Both groups show that intestinal stem cell-specific activation of Wnt leads to very efficient adenoma formation. Furthermore, Barker et al (2008) specifically compare this rate of adenoma formation to that following deletion of $A p c$ in transit-amplifying cells, the latter being greatly reduced. These experiments therefore strongly suggest the normal stem cell as the cell of origin for neoplasia, and that transformation of the intestinal stem cell is a primary route to intestinal neoplasia. These data also support the cancer stem cell concept in which a stem cell/progenitor cell hierarchy is maintained in early adenomas.

\section{REFERENCES}

Al-Hajj M, Wicha M, Benito-Hernandez A, Morrison S, Clarke M (2003) Prospective identification of tumourigenic breast cancer cells. Proc Nat Acad Sci USA 100: 3983-3988

Barker N, Ridgway R, van Es J, van de Wetering M, Begthel H, van den Born M, Danenberg E, Clarke AR, Sansom OJ, Clevers H (2008) Crypt stem cells as the cells-of-origin of intestinal cancer. Nature (in press), doi:10.1038/nature07602

Barker N, van Es JH, Kuipers J, Kujala P, van den Born M, Cozijnsen M, Haegebarth A, Korving J, Begthel H, Peters PJ, Clevers H (2007) Identification of stem cells in small intestine and colon by marker gene Lgr5. Nature 449: $1003-1007$

Blanpain C, Lowry WE, Geoghegan A, Polak L, Fuchs E (2004) Self-renewal, multipotency, and the existence of two cell populations within an epithelial stem cell niche. Cell 118: $635-648$

Bonnet D, Dick JE (1997) Human acute myeloid leukemia is organized as a hierarchy that originates from a primitive hematopoietic cell. Nat med 3: $730-737$

Clarke AR (2006) Wnt signalling in the mouse intestine. Oncogene 25: $7512-7521$

Clayton E, Doupe DP, Klein AM, Winton DJ, Simons BD, Jones PH (2007) A single type of progenitor cell maintains normal epidermis. Nature 446: $185-189$

Cotsarelis G, Cheng SZ, Dong G, Sun TT, Lavker RM (1989) Existence of slowcycling limbal epithelial basal cells that can be preferentially stimulated to proliferate: implications on epithelial stem cells. Cell 57: $201-209$

Cotsarelis G, Sun TT, Lavker RM (1990) Label-retaining cells reside in the bulge area of pilosebaceous unit: implications for follicular stem cells, hair cycle, and skin carcinogenesis. Cell 61: 1329-1337

Dor Y, Brown J, Martinez OI, Melton DA (2004) Adult pancreatic beta-cells are formed by self-duplication rather than stem-cell differentiation. Nature 429: 41-46

He XC, Yin T, Grindley JC, Tian Q, Sato T, Tao WA, Dirisina R, PorterWestpfahl KS, Hembree M, Johnson T, Wiedemann LM, Barrett TA,

\section{SUMMARY}

Somatic stem cells are now being identified with increasing confidence across a range of tumour prone tissues. For many of these same tissues, cancer stem cells have been identified with varying degrees of confidence. Although ultimate proof of the cancer stem cell is lacking for most of these tissues, the characteristics of these putative populations share at least some characteristics with normal stem cells. This suggests either that cancer stem cells directly originate from transformed somatic stem cells, or that there is a measure of convergent 'evolution' of the two stem cell types. Given the high turnover nature of many of these tissues, it is tempting to speculate that high activity within the stem cell compartment directly translates into an increased susceptibility to transformation. However, as yet there is little direct evidence to confirm or refute this.

The parallels existing between the two cell types do have implications for tumour therapy. Existing strategies have been developed to target the majority of cells within the tumour, as they are often identified through their ability to shrink tumour mass. However, this may only serve to de-bulk the tumour, potentially leaving cancer stem cells undamaged and so allow relapse of the tumour. This problem can potentially be solved by developing strategies that specifically target the cancer stem cell population. However, given the overlaps discussed in this review, it will be critical that these therapies do not also catastrophically impair the normal somatic stem population.

\section{ACKNOWLEDGEMENTS}

We thank to Nick Barker for information on Lgr5 and critical reading of this article.
Hood L, Wu H, Li L (2007) PTEN-deficient intestinal stem cells initiate intestinal polyposis. Nat Genet 39: 189-198

Hochedlinger K, Blelloch R, Brennan C, Yamada Y, Kim M, Chin L, Jaenisch $\mathrm{R}$ (2004) Reprogramming of a melanoma genome by nuclear transplantation. Genes Dev 18: $1875-1885$

Isaacs J (1985) Benign Prostatic Hyperplasia, Vol. 2nd edn. US Department Health Human Services: Washington, DC

Jaks V, Barker N, Kasper M, Clevers H, Toftgard R (2007) LGR5 marks cycling hair-follicle stem cells. Unpublished

Kelly PN, Dakic A, Adams JM, Nutt SL, Strasser A (2007) Tumor growth need not be driven by rare cancer stem cells. Science 317(5836): 337

Kim CF, Jackson EL, Woolfenden AE, Lawrence S, Babar I, Vogel S, Crowley D, Bronson RT, Jacks T (2005) Identification of bronchioalveolar stem cells in normal lung and lung cancer. Cell 121: 823-835

Lawson D, Xin L, Lukacs R, Cheng D, Witte O (2007) Isolation and functioanl characterisation of murine prostate stem cells. Proc Natl Acad Sci USA 104: $181-186$

Malanchi I, Peinado H, Kassen D, Hussenet T, Metzger D, Chambon P, Huber M, Hohl D, Cano A, Birchmeier W, Huelsken J (2008) Cutaneous cancer stem cell maintenance is dependent on beta-catenin signalling Nature 452: 650-653.

Morris RJ, Liu Y, Marles L, Yang Z, Trempus C, Li S, Lin JS, Sawicki JA Cotsarelis G (2004) Capturing and profiling adult hair follicle stem cells. Nat Biotechnol 22: $411-417$

Muncan V, Sansom OJ, Tertoolen L, Phesse TJ, Begthel H, Sancho E, Cole AM, Gregorieff A, de Alboran IM, Clevers H, Clarke AR (2006) Rapid loss of intestinal crypts upon conditional deletion of the Wnt/Tcf-4 target gene c-Myc. Mol Cell Biol 26: 8418-8426

Neuringer IP, Randell SH (2004) Stem cells and repair of lung injuries. Resp Res 5: 6

O'Brien CA, Pollett A, Gallinger S, Dick JE (2007) A human colon cancer cell capable of initiating tumour growth in immunodeficient mice. Nature 445: $106-110$ 
Oshima H, Rochat A, Kedzia C, Kobayashi K, Barrandon Y (2001) Morphogenesis and renewal of hair follicles from adult multipotent stem cells. Cell 104: 233-245

Oskarsson T, Essers MA, Dubois N, Offner S, Dubey C, Roger C, Metzger D, Chambon P, Hummler E, Beard P, Trumpp A (2006) Skin epidermis lacking the c-Myc gene is resistant to Ras-driven tumorigenesis but can reacquire sensitivity upon additional loss of the p21Cip1 gene. Genes Dev 20: 2024-2029

Potten CS, Booth C, Pritchard DM (1997) The intestinal epithelial stem cell: the mucosal governor. Int J Exp Pathol 78: 219-243

Potten CS, Owen G, Booth D (2002) Intestinal stem cells protect their genome by selective segregation of template DNA strands. J Cell Sci 115: $2381-2388$

Reya T, Morrison SJ, Clarke MF, Weissman IL (2001) Stem cells, cancer, and cancer stem cells. Nature 414: 105-111

Reynolds BA, Weiss S (1996) Clonal and population analyses demonstrate that an EGF-responsive mammalian embryonic CNS precursor is a stem cell. Dev biol 175: $1-13$

Ricci-Vitiani L, Lombardi DG, Pilozzi E, Biffoni M, Todaro M, Peschle C, De Maria R (2007) Identification and expansion of human colon-cancerinitiating cells. Nature 445: $111-115$

Richardson GD, Robson CN, Lang SH, Neal DE, Maitland NJ, Collins AT (2004) CD133, a novel marker for human prostatic epithelial stem cells. J Cell Sci 117: $3539-3545$

Ro S, Rannala B (2004) A stop-EGFP transgenic mouse to detect clonal cell lineages generated by mutation. EMBO Rep 5: 914-920

Sangiorgi E, Capecchi MR (2008) Bmil is expressed in vivo in intestinal stem cells. Nat Genet 7: $915-920$

Sansom OJ, Meniel VS, Muncan V, Phesse TJ, Wilkins JA, Reed KR, Vass JK, Athineos D, Clevers H, Clarke AR (2007) Myc deletion rescues Apc deficiency in the small intestine. Nature 446: 676-679

Sansom OJ, Reed KR, Hayes AJ, Ireland H, Brinkmann H, Newton IP, Batlle E, Simon-Assmann P, Clevers H, Nathke IS, Clarke AR, Winton DJ (2004) Loss of Apc in vivo immediately perturbs Wnt signaling, differentiation, and migration. Genes Dev 18: 1385-1390

Scadden DT (2006) The stem-cell niche as an entity of action. Nature 441: $1075-1079$
Shackleton M, Vaillant F, Simpson KJ, Stingl J, Smyth GK, Asselin-Labat ML, Wu L, Lindeman GJ, Visvader JE (2006) Generation of a functional mammary gland from a single stem cell. Nature 439: 84-88

Singh SK, Clarke ID, Terasaki M, Bonn VE, Hawkins C, Squire J, Dirks PB (2003) Identification of a cancer stem cell in human brain tumors. Cancer Res 63: $5821-5828$

Singh SK, Hawkins C, Clarke ID, Squire JA, Bayani J, Hide T, Henkelman RM, Cusimano MD, Dirks PB (2004) Identification of human brain tumour initiating cells. Nature 432: 396-401

Solter D (2006) From teratocarcinomas to embryonic stem cells and beyond: a history of embryonic stem cell research. Nat Rev Genet 7: 319-327

Stingl J, Eirew P, Ricketson I, Shackleton M, Vaillant F, Choi D, Li HI, Eaves CJ (2006) Purification and unique properties of mammary epithelial stem cells. Nature 439: 993 - 997

Toms JR (ed). (2004) CancerStats Monograph 2004. Cancer Research UK: London

Tsujimura A, Fujita K, Komori K, Takao T, Miyagawa Y, Takada S, Matsumiya K, Nonomur N, Okuyama A (2007) Prostatic stem cell marker identified by cDNA microarray in mouse. J Urol 178: 686-691

Wernig M, Meissner A, Foreman R, Brambrink T, Ku M, Hochedlinger K, Bernstein BE, Jaenisch $\mathrm{R}$ (2007) In vitro reprogramming of fibroblasts into a pluripotent ES-cell-like state. Nature 448: $318-324$

Xin L, Lawson DA, Witte ON (2005) The Sca-1 cell surface marker enriches for a prostate-regenerating cell subpopulation that can initiate prostate tumorigenesis. Proc Natl Acad Sci USA 102: 6942-6947

Zucchi I, Sanzone S, Astigiano S, Pelucchi P, Scotti M, Valsecchi V, Barbieri O, Bertoli G, Albertini A, Reinbold RA, Dulbecco R (2007) The properties of a mammary gland cancer stem cell. Proc Natl Acad Sci USA 104: $10476-10481$

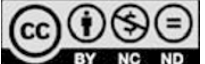

This work is licensed under the Creative Commons Attribution-NonCommercial-NoDerivs 3.0 License. To view a copy of this license, visit http://creativecommons.org/ licenses/by-nc-nd/3.0/ 